\title{
A novel heat exchanger concept for latent heat thermal energy storage in solar power towers: modelling and performance comparison
}

\author{
Heinrich Badenhorst* \\ Department of Chemical Engineering, University of Pretoria, Lynnwood Road, Pretoria, 0083, South \\ Africa
}

\section{Highlights}

- Study introduces spray crystallization as phase change heat recovery option.

- Can be directly incorporated into tower of central power tower designs.

- Particle diameter found to be largest single influence of tower height.

- Prilling feed system identified as critical for further investigation.

- Best case result indicates a $20 \%$ reduction in plant capital cost is achievable.

\begin{abstract}
This study presents an innovative new alternative for utilizing phase change materials as energy storage media in solar power towers. The solar power tower prilling or granulation concept combines the existing molten salt design with a prilling tower incorporated into the central receiver. In this way heat transfer limitations normally associated with these systems can be overcome since only very small particles (diameter 1-2 $\mathrm{mm}$ ) are utilized. Three design cases were considered and a detailed model of the process was developed. The model demonstrates the design dependence on several key variables including particle diameter and the necessity of considering the system in conjunction with the steam generation cycle. Pinch considerations within this cycle and the tower itself determine the operational feasibility. It was found that the receiver design and prilling feed systems are crucial aspects which must be investigated further to refine the concept design and complete a full techno-economic assessment and optimization. The "best case scenario" resulted in a reduction of the circulating salt flow by one third compared to the base case. Preliminary indications are that this would result in a $20 \%$ reduction of the
\end{abstract}

\footnotetext{
* Corresponding author. Tel: +27 12420 4989. Fax: +27 12420 2516. E-mail: carbon@up.ac.za
} 
overall plant capital cost, but additional costs such as solids handling and a complex receiver design have to be taken into account.

Keywords: LHTES; solar power tower; phase change material; prilling

\section{Introduction}

Recently, a lot of research has been aimed at developing renewable resources such as solar energy [1,2]. Concentrated solar power (CSP) technologies offer options for high efficiency electricity generation. Solar power towers (SPTs) can achieve higher temperatures and hence higher Carnot efficiencies than linear Fresnel or parabolic trough systems [3]. The approach does not require expensive parabolic mirrors and only a single central receiver is needed, as opposed to parabolic dish units. From this point of view SPTs have the greatest potential for efficiency improvement and levelised cost of electricity (LCOE) reduction on an industrial scale among all the CSP technologies $[4,5]$.

Arguably the most state of the art version of this technology currently in operation is the Gemasolar plant in Andalusia, Spain [6]. It is the first commercial-scale plant in the world to apply central tower receiver and molten salt heat storage technology. The central receiver is $140 \mathrm{~m}$ high and heats a liquid salt stream from 290 to $565{ }^{\circ} \mathrm{C}$, which is in turn used to generate steam to drive a conventional turbine system. In order to achieve a high capacity factor, the plant also has a molten salt storage system which permits electricity generation for up to 15 hours without any sunlight [7-9].

The most significant obstacle hindering wide scale implementation of renewable technologies in general probably still is energy storage [10]. Due to the variable and cyclic nature of solar resources, energy collection and storage is essential. In general, the availability of solar energy does not coincide with the periods of peak energy consumption in the late afternoon to evening. To ensure that non-renewable resources are not used during these periods, efficient storage and rapid availability are the key to increasing the utilization of renewable options.

The percentage contribution of the salt and associated equipment to the overall capital cost of these salt based systems can range from $20 \%$ for no storage up to over $30 \%$ for 15 hours of storage $[2,5,11]$. Thus any reduction in the quantity of salt required will lead to a significant decrease in the capital cost of the plant. The key to 
achieving this cost reduction is through an increase in energy density. In the case of the Gemasolar plant energy is solely stored as sensible heat. Thus the only way to increase the amount of energy stored per unit mass of salt is by increasing the temperature range. Unfortunately, the nitrate based salts currently in use undergo thermal degradation beyond the current operating range.

An attractive alternative is to exploit latent heat to achieve high energy densities through the use of phase change materials (PCMs) [12]. During the transition from solid to liquid energy is stored and then recovered during the reverse transformation. However, the low thermal conductivity of these materials is a significant deficiency [13] making rapid energy recovery very difficult. To overcome this limitation recent research has increasingly focused on developing composites, to improve the thermal performance of the PCMs [14-19]. Invariably, however, there are limits to the extent to which an additive can enhance the thermal conductivity at cost-effective loadings.

This problem calls for a revolution in the conventional approach to heat exchanger design which was not developed for liquid to solid phase transitions. From an energy density perspective, the ideal system would utilize both latent and sensible heat, thereby storing the maximum amount of energy per unit mass. Prilling or spray crystallization is a technique commonly used in the manufacture of fertilizers and detergents [20]. It is a granulation process in which a melt is sprayed to form small size droplets in a cooling medium, usually air. This is done at the top of a tall tower and the spherical drops are allowed to fall to ground level. The droplets rapidly cool as they descend through the uprising air, eventually solidifying and settling on the tower floor.

The droplets are formed by pumping the liquid through a perforated, rotating cylinder. The droplet size distribution can be controlled using the correct pressure drop and hole size leading to suitable breakup of the liquid jet [21, 22]. Invariably a particle size range is obtained but prill diameters are usually in the range of 1 to 2.5 $\mathrm{mm}$. Comprehensive data on the prilling process is not readily available in literature since the technology development of this process is limited by the small number of companies within this industry. However, a few modelling and experimental studies are available [23-28] including a mathematical model for a urea prilling process with a capacity of 1500 metric tons per day in a $50 \mathrm{~m}$ high tower [29]. 
The small particle size obtained from this technique coupled with the high convective heat transfer coefficients that can be achieved make this an excellent process for rapidly extracting the maximum energy from a molten salt. The objective of this investigation is to determine if it is feasible to use a prilling tower inside a solar power tower to recover latent and sensible heat from a liquid salt stream. To achieve this, a model of the process was developed using the physical and operational data of the Gemasolar plant as a base case. Three possible implementations are considered: retrofitting the Gemasolar plant, a greenfields design and an idealized system.

Retrofitting of the existing plant highlights the potential savings which could be incurred by utilizing the enthalpy of fusion in addition to the sensible heat currently used. It is proposed that the plant runs under very similar conditions to its current operation, with the notable exception that the tower is used for prilling and the solar receiver is modified to accommodate solid particles. For this case the salt composition, tower height, steam conditions and other operating parameters are predetermined and set in accordance with the current Gemasolar plant. The analysis is done purely on an energy balance basis and the tower is not simulated in detail.

Given the novelty of the proposed concept, the Gemasolar design parameters are not necessarily optimal for such a configuration. Most notably would be the choice of salt or PCM. Thus as an alternative a greenfields or clean slate design is considered. In this case a more suitable PCM is chosen, namely a metal halide salt. These salts provide a significantly higher enthalpy of fusion and phase transition temperature. The tower diameter is kept the same as the Gemasolar plant but the other plant parameters are modified to best accommodate the salt. This includes a detailed simulation of the prilling process to estimate the required tower height.

Finally an idealized or "best-case" scenario is considered. This case represents an extension of the greenfields design by adding a secondary unit to recover sensible heat from the salt. The operating parameters are adjusted to realize a feasible design. While this situation may not be practically or economically feasible, it does provide an estimate of the absolute minimum PCM required for the same system power output. Again the analysis is done purely on an energy balance basis and the tower is not simulated in detail. 
In addition, the sensitivity of the solar power tower prilling design to a variety of factors including particle size, tower pressure, inlet/outlet temperatures and inlet velocity is also studied based on the greenfields design. The aim of this work is to identify the key regions of the design which require further development and experimental verification. Future work will focus on addressing each aspect in more detail to enable a comprehensive system design which in turn will allow a sensible techno-economic evaluation.

\section{Model development and case studies}

\subsection{Base case: Gemasolar}

As a first step it is necessary to define the operating conditions of the steam system, the operation of this part of the process is assumed to be independent of the energy storage side. Thus each of the three proposed designs must at all times conform to the steam generation prerequisites. Physical and operational data for the Gemasolar plant are readily available [7-9]. The key plant design parameters are summarized in Table 1.

Table 1: Gemasolar design parameters

\begin{tabular}{|c|c|}
\hline Tower height $[\mathrm{m}]$ & 140 \\
\hline Receiver diameter $[\mathrm{m}]$ & 8.9 \\
\hline Receiver height $[\mathrm{m}]$ & 14.2 \\
\hline Power block output $[\mathrm{MWe}]$ & 20 \\
\hline Turbine & Siemens SST-600 \\
\hline Salt composition & $50 \% \mathrm{NaNO}_{3}, 40 \% \mathrm{KNO}_{3}$ \\
\hline Hot salt temperature $\left[{ }^{\circ} \mathrm{C}\right]$ & 290 \\
\hline Cold salt temperature $\left[{ }^{\circ} \mathrm{C}\right]$ & $221-238$ \\
\hline Phase transition temperature $\left[{ }^{\circ} \mathrm{C}\right]$ & 15 \\
\hline Storage Time $[\mathrm{h}]$ & \\
\hline
\end{tabular}

The power block electrical output is $20 \mathrm{MWe}$, assuming a 33\% efficiency this would require a heat input of $60 \mathrm{MWt}$. This is conservative since the operating efficiency of the turbine is likely higher than this value, thus the thermal requirement and consequently the salt circulation rate would be less. The impact of turbine efficiency was not investigated but an increase in efficiency would lead to a decrease 
in the salt required directly proportional to the increased thermal load (assuming the power block output is fixed). The simplified operation of a Siemens SST-600 turbine [30] is shown in Figure 1, where HP, IP and LP refer to the high, intermediate and low pressure sections respectively.
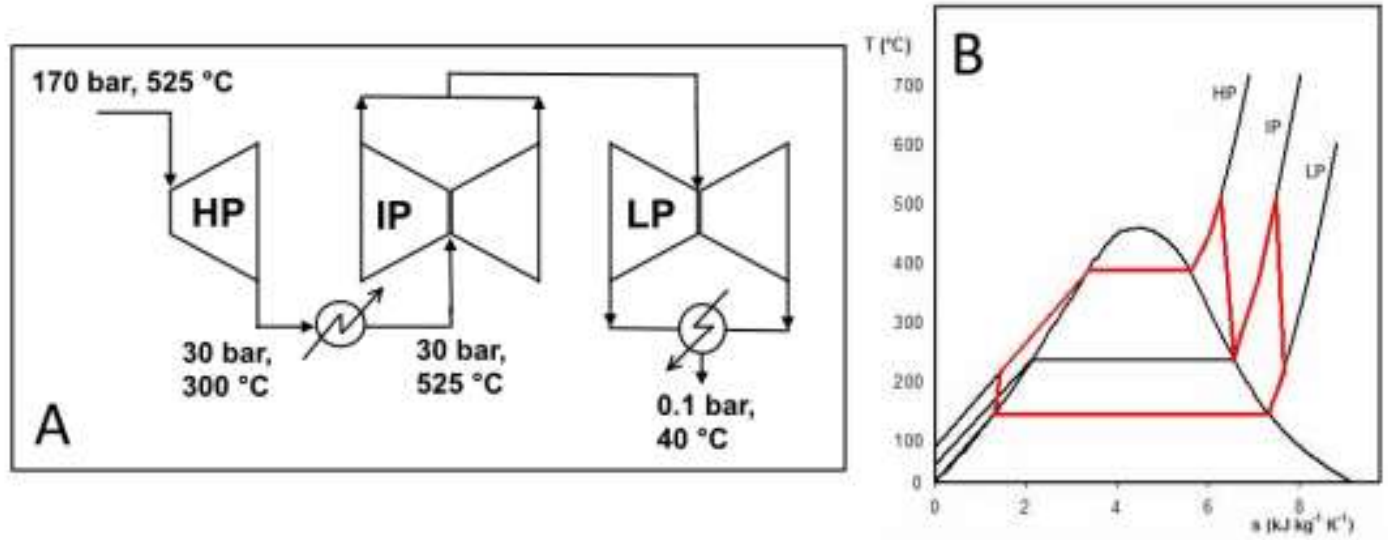

Fig. 1: (A) Schematic of turbine operation and (B) corresponding T-S diagram.

Based on the inlet and outlet conditions given in Figure 1, the steam flow rate required to deliver a heat input of $60 \mathrm{MWt}$ can be calculated as $17.4 \mathrm{~kg} \cdot \mathrm{s}^{-1}$, i.e. under peak load conditions. In addition, the operation of the salt-steam heat exchanger system is given below in Figure 2 to match the turbine operation.

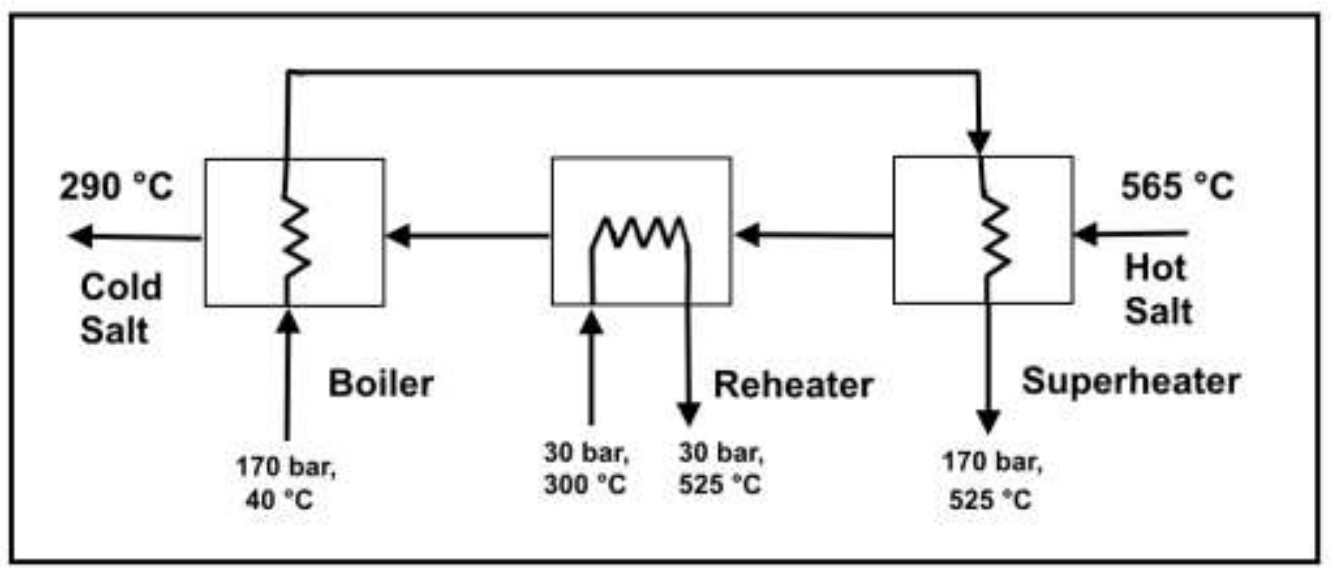

Fig. 2: Schematic of salt-steam heat exchanger system.

The thermal properties of the salt are given in Table 2, using these values the salt flow rate required to deliver the thermal input to the steam system may be calculated from an energy balance as $150 \mathrm{~kg} . \mathrm{s}^{-1}$. 
Table 2: Gemasolar salt properties

\begin{tabular}{|c|c|}
\hline Density $\left[\mathrm{kg} \cdot \mathrm{m}^{-3}\right]$ & 1900 \\
\hline Phase transition temperature $\left[{ }^{\circ} \mathrm{C}\right]$ & $221-238$ \\
\hline Enthalpy of fusion $\left[\mathrm{kJ} \cdot \mathrm{kg}^{-1}\right]$ & 161 \\
\hline Liquid heat capacity $\left[\mathrm{J} \cdot \mathrm{kg}^{-1} \cdot \mathrm{K}^{-1}\right]$ & 1460 \\
\hline Solid heat capacity $\left[\mathrm{J} \cdot \mathrm{kg}^{-1} \cdot \mathrm{K}^{-1}\right]$ & 1300 \\
\hline Thermal conductivity $\left[\mathrm{W} \cdot \mathrm{m}^{-1} \mathrm{~K}^{-1} \cdot\right]$ & 0.52 \\
\hline
\end{tabular}

\subsection{Model formulation}

For detailed modelling it is necessary to develop a fundamental model of the prilling process in order to simulate the tower and calculate the required height. A basic schematic of the prilling process is given in Figure 3.

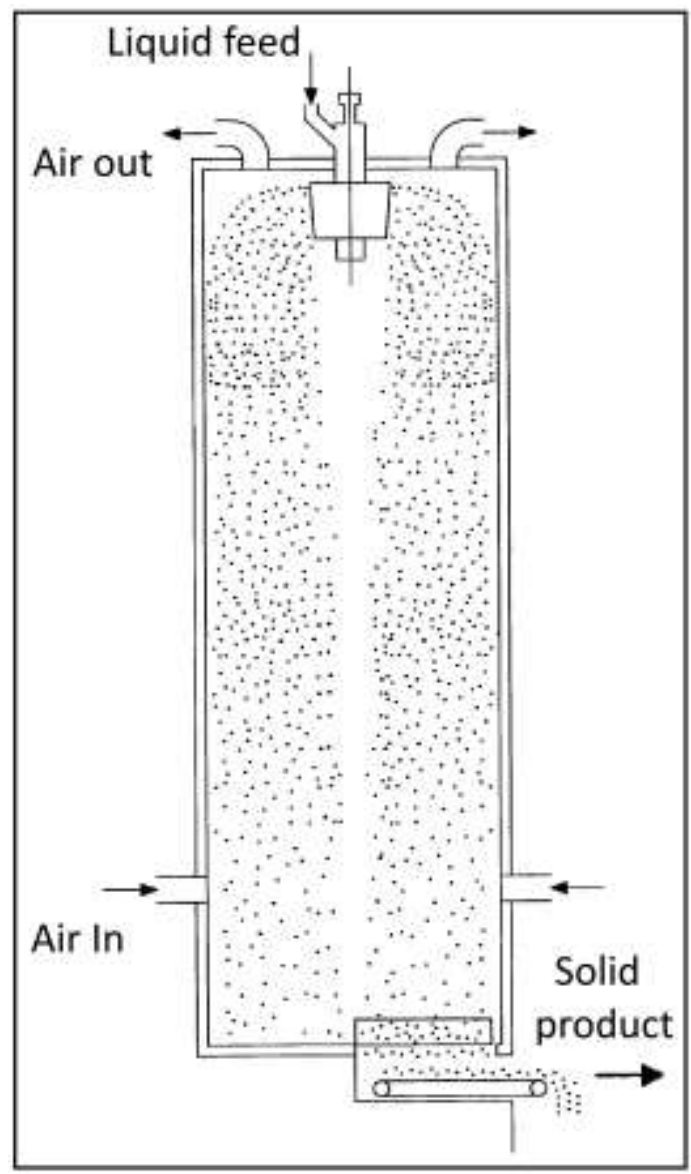

Fig. 3: Prilling process.

To simulate the process, the continuity equations for mass, momentum and energy transfer are solved simultaneously. A steady state operating condition for the tower is assumed. For both salts considered in this investigation and for a particle size range of 
1 to $2 \mathrm{~mm}$, the Biot numbers are very close to 0.1 (heat transfer coefficient $\sim 500$ $\mathrm{W} . \mathrm{m}^{-2} \mathrm{~K}^{-1}$ [29]). Thus the heat transfer resistance within the sphere may be considered negligible and the particles are assumed to have a uniform temperature distribution. Previous work [31] has demonstrated that the thermodynamic behaviour of the particle can be accurately modelled using the effective heat capacity method which is used in this investigation. The gas phase mass balance anywhere in the tower is given by:

$$
\dot{m}=A_{\text {tower }} \rho v
$$

Where $\dot{m}$ is the mass flow rate, $A_{\text {tower }}$ is the tower cross-sectional area, $\rho$ is the density and $v$ is the superficial gas velocity. All units in this and the following equations are in the SI standard. Thus assuming ideal gas behaviour the gas velocity at any point in the column is given by:

$$
v=\frac{\dot{m} R T}{A_{\text {tower }} P M M}
$$

Where $R$ is the ideal gas constant, $T$ is the temperature in Kelvin, $P$ is the pressure and $M M$ is the molecular mass of the gas species. The gas phase momentum balance across a differential element may be stated as:

$$
P A_{\text {tower }}-(P+d P) A_{\text {tower }}-\tau_{W}\left(\pi D_{\text {tower }}\right) d z=\dot{m}(v+d v-v)
$$

The wall shear stress $\left(\tau_{W}\right)$ can be approximated by the Hagen-Poiseuille equation, assuming the flow has a low Reynolds number which will later be shown to be the case. Furthermore, the frictional force experienced by the gas due to the particles must be accounted for, this results in a slightly modified Ergun equation [32]:

$$
d P+\frac{32 \mu v}{D_{\text {tower }}^{2}} d z+\frac{180 \mu v}{D_{p}^{2}}\left(\frac{(1-\varepsilon)^{2}}{\varepsilon^{3}}\right) d z+\frac{\rho}{2} v d v=0
$$

Where $\mu$ is the gas viscosity, $D_{\text {tower }}$ is the tower diameter, $D_{p}$ is the particle diameter, $z$ is the tower height and $\varepsilon$ is the void fraction. Similarly the energy balance for the gas across a differential section of the column may be derived as:

$$
d h+g d z+\frac{1}{2} v d v+\frac{\dot{q}}{\dot{m}}=0
$$

Here $\dot{q}$ is the rate of heat transfer from solid to gas phase and $d h$ is the enthalpy change of the gas which is also equal to $C_{p} d T$. These three equations $(2,4 \& 5)$ must be solved simultaneously for the gas phase. In addition, a force balance can be done on the solid particles under free fall. Three forces should be taken into account, 
gravity, drag and buoyancy. Given the large density difference between the gas and solid the latter may be considered negligible. Thus the force balance across a differential element becomes:

$$
m_{p} \frac{d v_{p}}{d t}=g m_{p}-\frac{1}{2} C_{D} \rho A_{p} v_{r e l} v_{p}
$$

Now $m_{p}$ is the particle mass, $v_{p}$ is the particle velocity, $C_{D}$ is the drag coefficient, $A_{p}$ is the particle surface area and $v_{r e l}$ is the relative velocity of the gas and solid. The drag coefficient can be calculated using the well-known formula for a sphere in external flow. The remaining expression is the energy balance for the solid, which for a given particle is simply:

$$
Q_{p}=h A_{p}\left(T_{p}-T\right)
$$

Where $Q_{p}$ is the heat transferred per particle and $T_{p}$ is particle temperature. This temperature change can be applied to the entire mass of solid to calculate the total energy transferred, $\dot{q}$. The heat transfer coefficient $h$ may be calculated using the widely used correlations for the Nusselt number [33], for example:

$$
N u=\frac{h L}{k}=2+0.6 \operatorname{Re}^{0.5} \operatorname{Pr}^{0.33}
$$

Where $\operatorname{Re}$ and $\operatorname{Pr}$ are the Reynolds and Prandtl numbers respectively and $L$ is the characteristic length of the particle. It is interesting to note that the thermal conductivity of the salt does not play a role in the estimation of the heat transfer coefficient. This is a well-established fact for fluidized bed designs [33]. These five equations can be solved simultaneously to generate the steady state pressure, temperature and velocity profiles of the gas and solid phases as a function of tower height. This detailed modelling is only done for the greenfields design.

\subsection{Case study 1: Retrofit Gemasolar}

The initial case study considered was the option of retrofitting the current Gemasolar plant with a prilling tower to recover additional heat from the existing hot salt stream. Conceptually the system would utilize the existing tower for prilling, thus operation would remain essentially the same, but the amount of salt needed will be reduced by the utilizing its heat of fusion in addition to the sensible heat currently used. The central receiver would have to be modified to accommodate the salt particles, a possible configuration is suggested later in section 2.6. However, several 
operational considerations become apparent which must be taken into account, since this configuration must still conform to the requirements of the steam turbine cycle. For example, as the hot salt flow rate is decreased, the intermediate temperatures after the superheater and reheater will also decrease in order to maintain the same duty. Thus it is possible that the salt temperature drops below the saturation temperature of steam at 170 bar before all of the steam is vaporized, thus resulting in an infeasible design. If it is assumed that the salt is cooled to its freezing temperature $\left(238^{\circ} \mathrm{C}\right)$ and fully solidified, this is indeed found to be the case. The additional energy storage afforded by this hypothetical step would potentially have led to a reduction in the required circulating salt flow to $94 \mathrm{~kg} \cdot \mathrm{s}^{-1}$, as determined from an energy balance.

Several options on the steam turbine side exist to deal with this, one of which would be to drop the pressure of the steam to allow vaporization at a lower temperature. However, this option would then require recompression of the superheated steam which would be excessively expensive compared to pumping liquid water to the required pressure. To keep the analysis simple an alternative would be to reduce the amount of heat recovered from the salt in the prilling tower. The salt enters the prilling column at $290{ }^{\circ} \mathrm{C}$ and it is reasonable to conclude that this would fix the maximum temperature to which the cold water from the turbine condenser could be heated. A minimum approach delta temperature $\left(\Delta \mathrm{T}_{\min }\right)$ should be specified and a conservative value of $25^{\circ} \mathrm{C}$ was chosen throughout this investigation. In reality the situation is more complex since a secondary fluid, e.g. cooling air is involved.

Nonetheless this places the maximum theoretical duty of the prilling column at 16.4 MW, which more realistically reduces the circulating salt flow to $109 \mathrm{~kg} . \mathrm{s}^{-1}$. For this case the hot salt can still fully vaporize the steam before its temperature falls below the saturation temperature of $350^{\circ} \mathrm{C}$. However, this situation is far from ideal since this heat load does not fully freeze the salt. It can be shown that only around half the latent heat is extracted and the solid fraction achieved is only $47 \%$. Even so, this already demonstrates the potential benefit of this approach as the required salt circulation rate is still reduced by $28 \%$ which would lead to a concurrent reduction in the mass of storage salt required. In addition, the analysis shows that it is critical to consider the operation of the steam heat exchanger network in conjunction with the prilling tower operation. As it is clear that this design is sub-optimal the prilling tower itself was not simulated in detail. 


\subsection{Case study 2: Greenfield design}

The second potential implementation which was explored is a completely new facility. This allows additional flexibility in terms of the salt selection. Potassium halide salts offer a comparable heat capacity to the current solar salt, but they have a significantly improved enthalpy of fusion. In addition, they are stable up to high temperatures and have approximately the same market value as the nitrate salts. For these reasons, a 55\% mixture of potassium fluoride and potassium chloride was chosen, for which the salt properties are given in Table 3.

Table 3: Potassium halide salt properties [34]

\begin{tabular}{|c|c|}
\hline Salt composition & $55 \% \mathrm{KF}, 45 \% \mathrm{KCl}$ \\
\hline Density $\left[\mathrm{kg} \cdot \mathrm{m}^{-3}\right]$ & 2255 \\
\hline Phase transition temperature $\left[{ }^{\circ} \mathrm{C}\right]$ & 605 \\
\hline Enthalpy of fusion $\left[\mathrm{kJ} \cdot \mathrm{kg}^{-1}\right]$ & 407 \\
\hline Liquid heat capacity $\left[\mathrm{J} \cdot \mathrm{kg}^{-1} \cdot \mathrm{K}^{-1}\right]$ & 1260 \\
\hline Solid heat capacity $\left[\mathrm{J} \cdot \mathrm{kg}^{-1} \cdot \mathrm{K}^{-1}\right]$ & 1000 \\
\hline Solid Thermal conductivity $\left[\mathrm{W} \cdot \mathrm{m}^{-1} \mathrm{~K}^{-1} \cdot\right]$ & 1.2 \\
\hline
\end{tabular}

A simple system design is demonstrated in Figure 4, the key considerations are the inlet and outlet temperatures of the gas and solid. All three heat exchangers for steam generation are accommodated in a single unit, very similar to current boiler operations for electricity generation. 


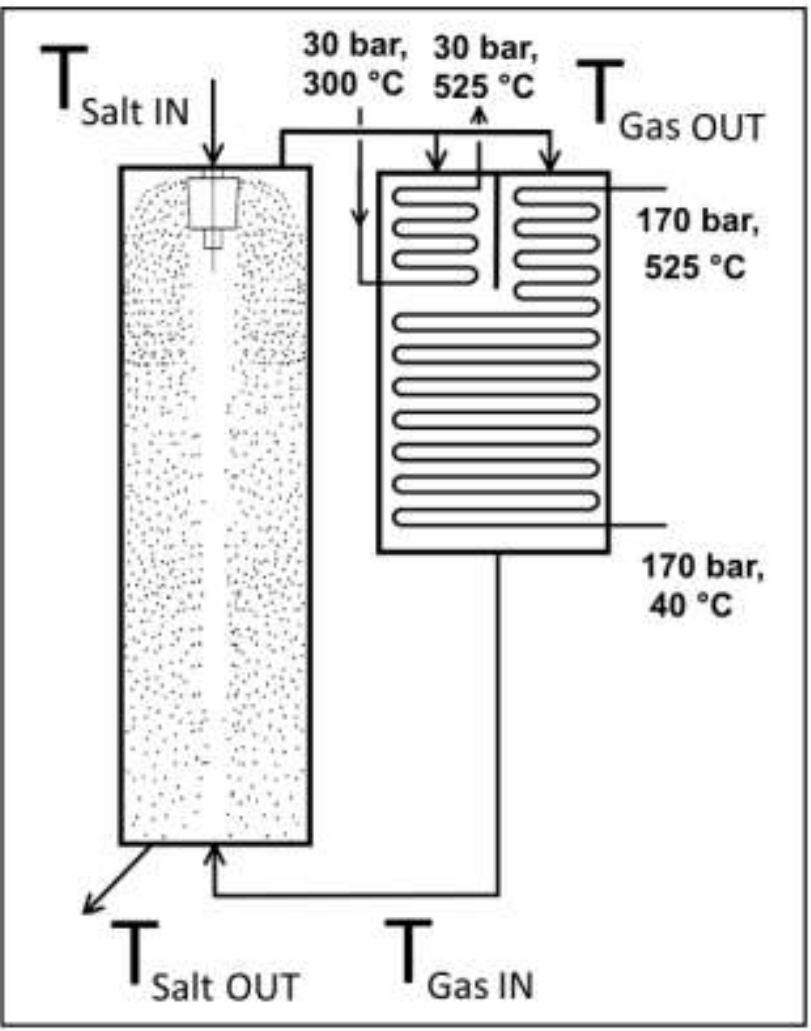

Fig. 4: LHTES system design.

Recent investigations have shown that $700{ }^{\circ} \mathrm{C}$ is approximately the maximum limit for economically using stainless steel in designs with high temperature molten salts [35-37]. For this reason a slightly more conservative temperature of $675^{\circ} \mathrm{C}$ is chosen as the maximum salt temperature, i.e. the salt inlet temperature. From an idealized perspective it would be optimal to reduce the salt outlet temperature to as close as possible to ambient, since this represents the maximum energy density. If fresh air is used as the coolant, this may be achievable. In keeping with the prior analysis, a minimum approach delta temperature $\left(\Delta \mathrm{T}_{\min }\right)$ of $25^{\circ} \mathrm{C}$ is used, which fixes the remaining temperatures. For this design it was unclear which gas should be used to extract the heat from the PCM, initially air was chosen. These values can then be used to calculate the salt and air flow rates at 55.8 and $96.0 \mathrm{~kg} . \mathrm{s}^{-1}$ respectively, as calculated from suitable energy balances. To assess the system a pinch analysis was done for the steam/air heat exchanger assuming constant heat capacities and this is shown in Figure 5. 


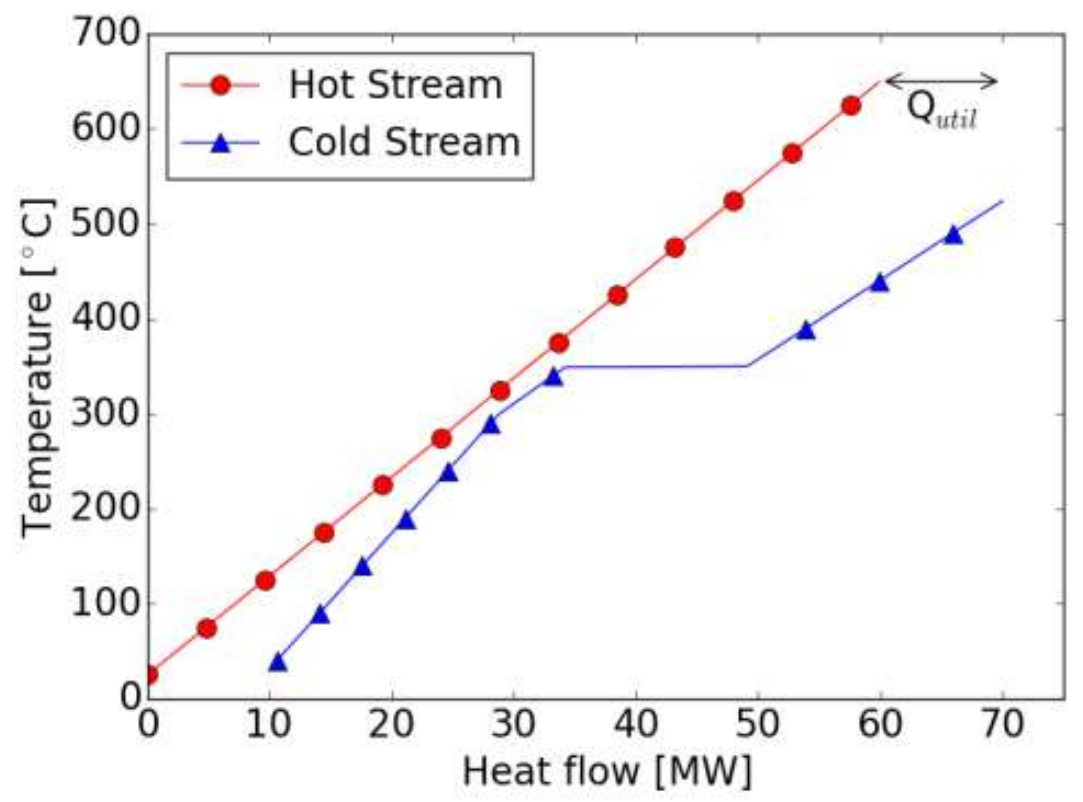

Fig. 5: Pinch analysis of steam/air system.

The pinch analysis demonstrates that if air is used as the coolant the system will require an additional 10.6 MW of hot utility to achieve the desired steam generation. This is due to the low heat capacity of air, as an alternative steam was chosen as the gas phase coolant since it has double the heat capacity. This does beg the question; why not use the turbine steam directly? While this is possible from a plant integration standpoint, from an operational perspective this could lead to corrosion and damage to the turbine due to fine solid carry over. For this reason a separate steam loop is considered which does not have the very high demineralized requirements associated with boiler feed water.

This does, however, place an additional constraint on the system: the saturation temperature of the coolant steam. A trade-off is possible between the chosen column pressure and the minimum gas inlet temperature. As the pressure is increased the heat capacity of the gas stream is further increased but the saturation temperature rises and thus the gas inlet temperature to the column (i.e. outlet temperature from the turbine steam unit) must also increase. As a starting point an operating pressure of 5 bar was chosen for the column. This puts the minimum coolant steam temperature at $175^{\circ} \mathrm{C}$ to avoid condensation and this fixes the salt outlet temperature at $200{ }^{\circ} \mathrm{C}$ via $\Delta \mathrm{T}_{\min }$. For this arrangement the new pinch analysis is given Figure 6. 


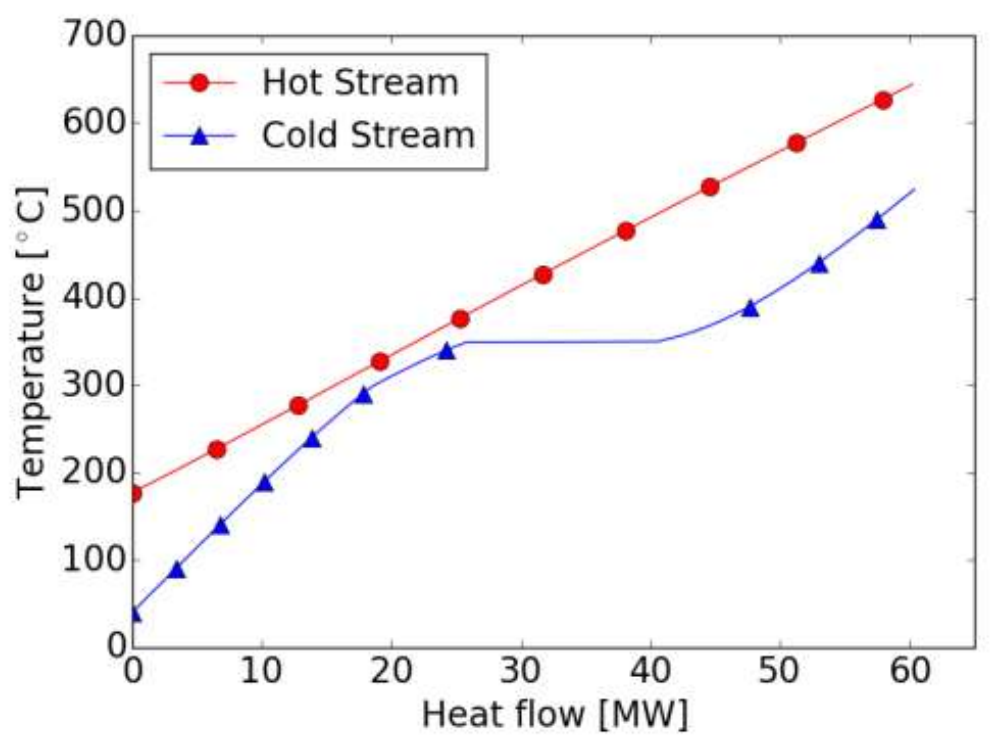

Fig. 6: Pinch analysis of steam/steam system.

In addition to the use of steam as opposed to air, this figure is compiled using the exact steam property values from the steam tables [38]. As can be seen this mainly has an impact on the region surrounding the phase change but the behaviour is still very similar to the assumption of constant heat capacities. For this configuration no additional heating is needed and the required salt and coolant steam flow rates are found to be 66.7 and $56.9 \mathrm{~kg} . \mathrm{s}^{-1}$ respectively.

Analysis of the proposed heat exchanger network was done and it was found that $36.8 \mathrm{~kg} . \mathrm{s}^{-1}$ of coolant steam is required for the reheater section, whilst $23.3 \mathrm{~kg} . \mathrm{s}^{-1}$ is used for superheat. This results in a combined temperature of $468^{\circ} \mathrm{C}$ at the inlet of the vaporizer and a gas phase temperature of above $350{ }^{\circ} \mathrm{C}$ after complete evaporation of the turbine steam. Thus this configuration is feasible and whilst the salt is now completely solidified, it is not cooled to ambient temperature. At the current flow rate this represents an additional $10 \mathrm{MW}$ of missed storage capacity. For this system the ideal scenario would be to utilize the central receiver tower for prilling.

\subsection{Case study 3: Ideal system}

In addition to the lost storage capacity, reducing the salt temperature to roughly ambient has several advantages: heat losses in the solids transport system will be minimal, thus no high temperature materials or insulation are required. The solids conveying and storage systems are also greatly simplified since a straightforward 
bucket/conveyer system can be used and an enclosed storage tank is not necessary. To recover the additional $10 \mathrm{MW}$ several idealized configurations were considered. Each of these secondary units make use of air as a cooling medium in addition to the coolant steam calculated for the greenfields design.

Firstly a slow moving bed arrangement where cooling is achieved through ambient air. This configuration proved infeasible since the required air flow rate is above the minimum fluidization velocity of the particles, thus they would be entrained in the carry over.

It may be possible to use a fluidized bed for heat recovery but this does not achieve as high an outlet air temperature as counter current exchange. This in turn limits the heat transfer to the cold water from the turbine condenser. The bed achieves a steady state operating temperature which is representative of the average cooling experienced by each particle in the bed. This temperature will not be close to the incoming salt temperature and thus the gas leaving the bed will not achieve this temperature. A fluidized bed system is much more suited to extracting heat at a constant temperature.

For the current system it may however be attractive to reduce the height of the prilling tower by adding a fluidized bed to the bottom of the tower itself. Here heat will be extracted virtually isothermally as the particles solidify. The feasibility and benefit of this design has recently been demonstrated [39] but unfortunately this system still suffers from a drawback in terms of the residence time of particles within the bed. This means that inevitably the particles leaving the fluidized bed will be solidified to varying extents. This problem can be overcome by cascading multiple fluidized beds in series to achieve a much narrower distribution [33]. Another critical consideration will be the determination of the solidification fraction which results in a particle wall which is strong enough to survive impact. The particle core should still be as molten as possible when the particle enters the fluidized bed but if the shell fractures the particles will agglomerate making fluidization and handling difficult.

For these reasons the best arrangement is a cooled moving bed where the required air flow rate can be largely reduced through the use of a cooling jacket and additional cooling tubes within the bed. The analysis of such a system was attempted but the system pinch again becomes an issue. As can be seen from Figure 6 the system is already operating very close to a pinch point around the vaporization step. If some of 
the turbine condenser outlet water was to be pre-heated the cold stream curve would shift to the left creating a pinch. This can be overcome by increasing the maximum allowable salt temperature and increasing the tower pressure which increases the coolant steam heat capacity.

The impact of increasing the steam pressure was found to be relatively small but by raising the pressure to $25 \mathrm{bar}$, increasing the salt temperature by $50{ }^{\circ} \mathrm{C}$ and relaxing the minimum approach delta temperature $\left(\Delta \mathrm{T}_{\min }\right)$ to $10^{\circ} \mathrm{C}$, it is possible to achieve a salt outlet temperature approaching ambient. This gives a "best case scenario" reduction of the circulating salt flow rate was calculated from an energy balance to be $53.2 \mathrm{~kg} . \mathrm{s}^{-1}$. Whilst this is a substantial decrease, the benefit must be weighed against the additional cost of the tower pressure rating, corrosion of materials and higher heat exchanger cost for a smaller approach temperature. Since this case represents an idealized system which is unlikely to be cost-effective, it was not simulated in detail.

\subsection{Possible receiver design}

To fully explore the feasibility of the proposed plant the receiver design must also be considered. A simplified receiver design for this system is displayed in Figure 7. 


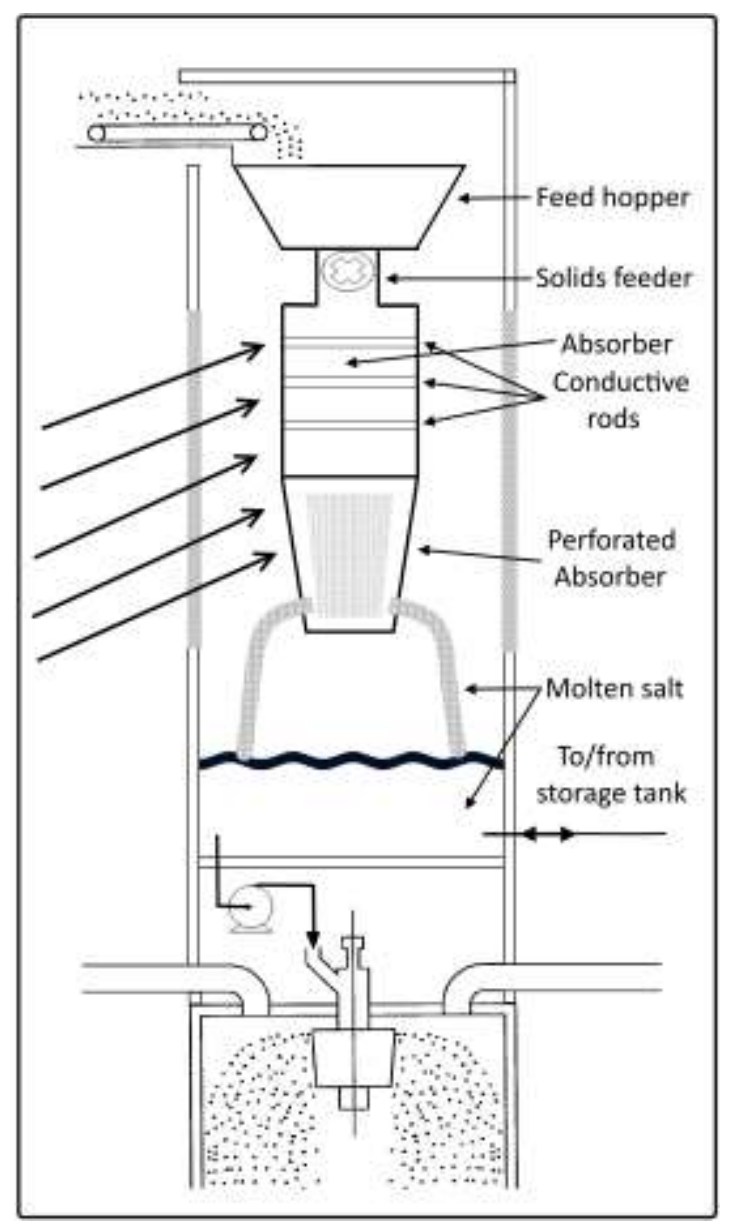

Fig. 7: Basic receiver design.

The prilled solid is accumulated in a feed hopper at the top of the solar tower. Its flow to the absorber is controlled by a rotary airlock feeder. The reason for this is that hot air can be circulated in the primary absorber to aid heat transfer from the walls and the heat pipes to the salt. The conductive rods are comprised of a highly conductive metal such as copper which conducts heat from the absorber shell to its interior. The rods can also be arranged to induce radial movement and mixing within the solid bed. The solid is gradually heated as it passes downward through the absorber which is subjected to high solar flux. The absorber can be cylindrical in order to absorb solar energy from a full $360^{\circ}$ solar field.

Near the bottom of the absorber the solid will melt and pass through a perforated section of the absorber into a molten salt accumulator. From here excess salt is sent to storage for use during the night whilst the rest is pumped through the prilling distributor. During periods of low solar irradiation molten salt can then be pumped from storage into the accumulator to continue operation. To a certain degree, the 
absorber section is also self-regulating during periods of irregular irradiance since the melting rate will naturally follow the heat flux incident on the absorber. If the current configuration is not sufficient to achieve the desired temperature a secondary absorber could be used where the molten salt is heated beyond its melting point.

With this simple arrangement it would be fairly easy to achieve continuous operation in a very similar fashion to the Gemasolar plant. A lot of uncertainty surrounds the proposed receiver design and a curtain absorber may be able of achieving much higher heat transfer rates. To date a few studies have been completed on solid curtain or falling particle absorber designs [40, 41]. It is possible to increase the absorptivity of the salts via the incorporation of additives such as carbon black. This does, however, place a limit on the operating temperature range where air can be used as the carbon would be oxidized.

Despite the work that has been published on the design of prilling distributors [21, 22] the material under consideration in this investigation is quite different from urea used to make fertilizer prills. Thus a lot of ambiguity also surrounds this aspect of the design and its practical feasibility. Definitely the receiver and prilling feed systems are the portions of the overall proposal with the highest level of doubt. Thus future experimental work must focus on these aspects to refine the viability of this concept plant.

\section{Detailed tower modelling and performance summary}

The prior analysis of the different cases was based purely on energy balances and pinch considerations. It would be convenient if the prilling operation can be achieved within a tower with dimensions similar to the Gemasolar plant. To reflect this the same tower diameter is used for modelling. This section conveys the results of the detailed simulation model developed in Section 2.2 as configured for the greenfields design. In addition, the system sensitivity to different key parameters is explored.

The simulation was verified against three urea prilling studies found in the limited available literature $[29,39,42]$. The granulation of urea is done in a system identical to the one proposed here: a tall tower with air flowing upward. Molten urea liquid is sprayed into the tower at the top and allowed to drop through the cool air, solidifying by the time it reaches the bottom. Mechanistically however the process is slightly different from the straightforward solidification of a salt. The liquid urea solution also 
contains water and biuret impurities which influences the solidification behaviour [29, 42]. The model parameters were adjusted to the values for urea and air, as well as the tower parameters for each of the different investigations found in literature. The column temperature prediction, displayed in Figure 8, shows good agreement with the observed temperature profile for dry urea prilling [39].
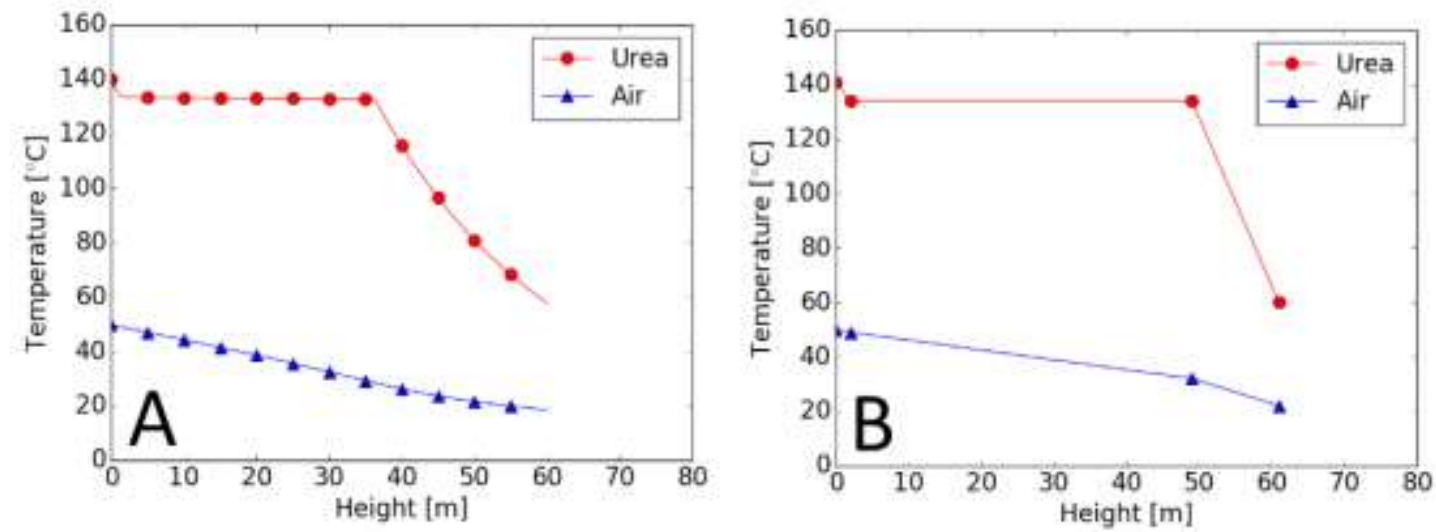

Fig. 8: (A) Predicted temperature profile for urea prilling (B) compared to approximated literature results [39].

Distance is measured from the top of the tower downward, i.e. the point where the hot material is introduced. Direct or quantitative comparison of the results cannot be done since the solidification of urea also involves the evaporation of water (neglected in this model) in addition to the phase transition, hence the longer plateau. Nonetheless, the model demonstrates good agreement with the tower height, inlet and outlet temperatures of both air and urea found in the additional two analyses. In addition, the simulation predicts the same correlations found in these two papers, namely that the Reynolds number increases with an increase in particle diameter whilst the heat transfer coefficient decreases, as illustrated in Figure 9. This is due to the direct proportionality of the Reynolds to particle diameter while the increase in Reynolds number and consequently Nusselt number is not enough to offset the inverse dependence of the heat transfer coefficient on the particle diameter. 


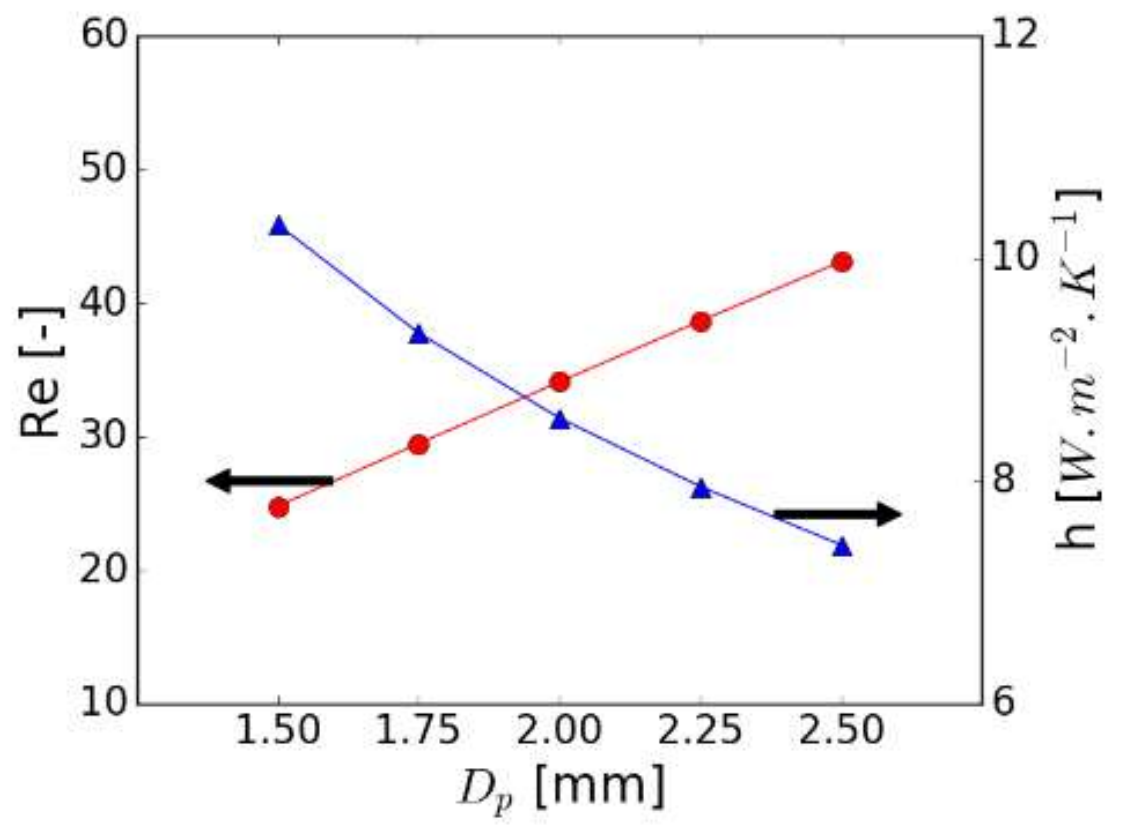

Fig. 9: Influence of particle size on urea prilling.

One of these studies [29] is based on a plant operating at roughly one third of the proposed mass flow rate used in the current investigation, this gives a good indication that an industry standard prilling feed system may be sufficient to achieve the design parameters. The simulated temperature profile for the greenfields design case study is shown in Figure 10, for this case a prill diameter of $1 \mathrm{~mm}$ is assumed.

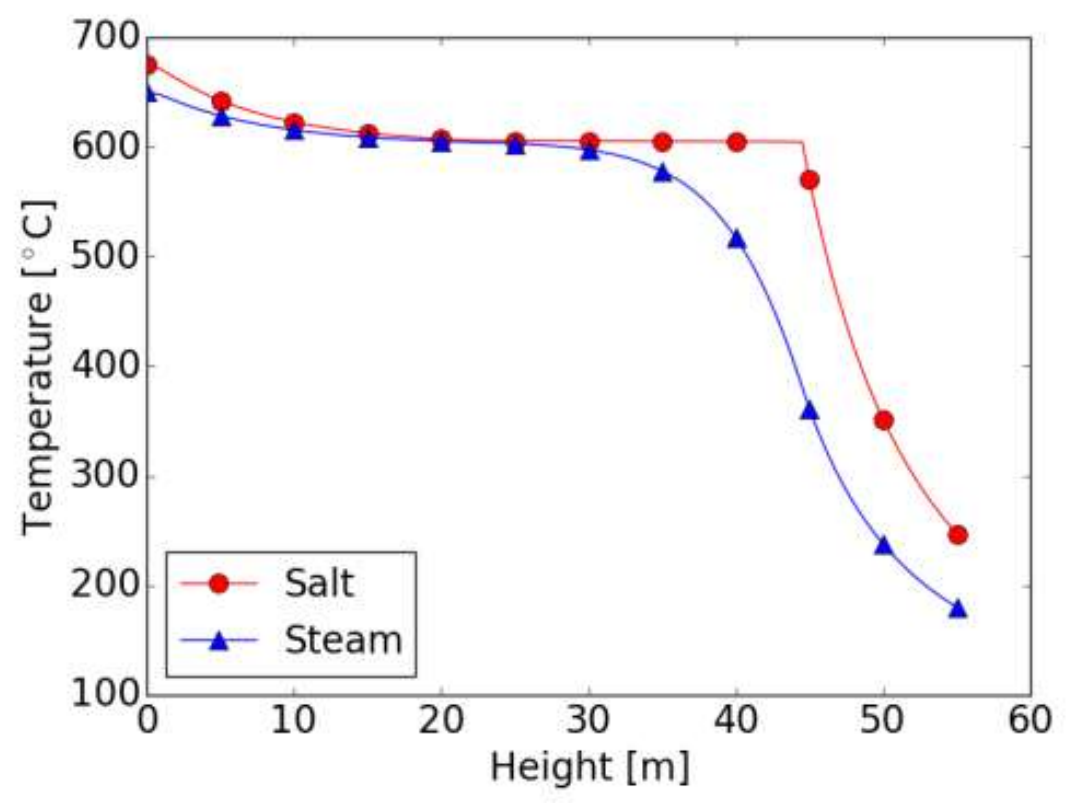

Fig. 10: Temperature profile for greenfields design. 
As can be seen from this figure, there is a slight issue with the design: a pseudopinch point is approached during the phase transition. At the given conditions, the air and salt temperatures approach each other too closely and heat exchange largely slows down. This results in a very long tower section required for this heat exchange zone. Theoretically increasing the final steam temperature slightly to $655{ }^{\circ} \mathrm{C}$ yields an infeasible design as demonstrated in Figure 11.

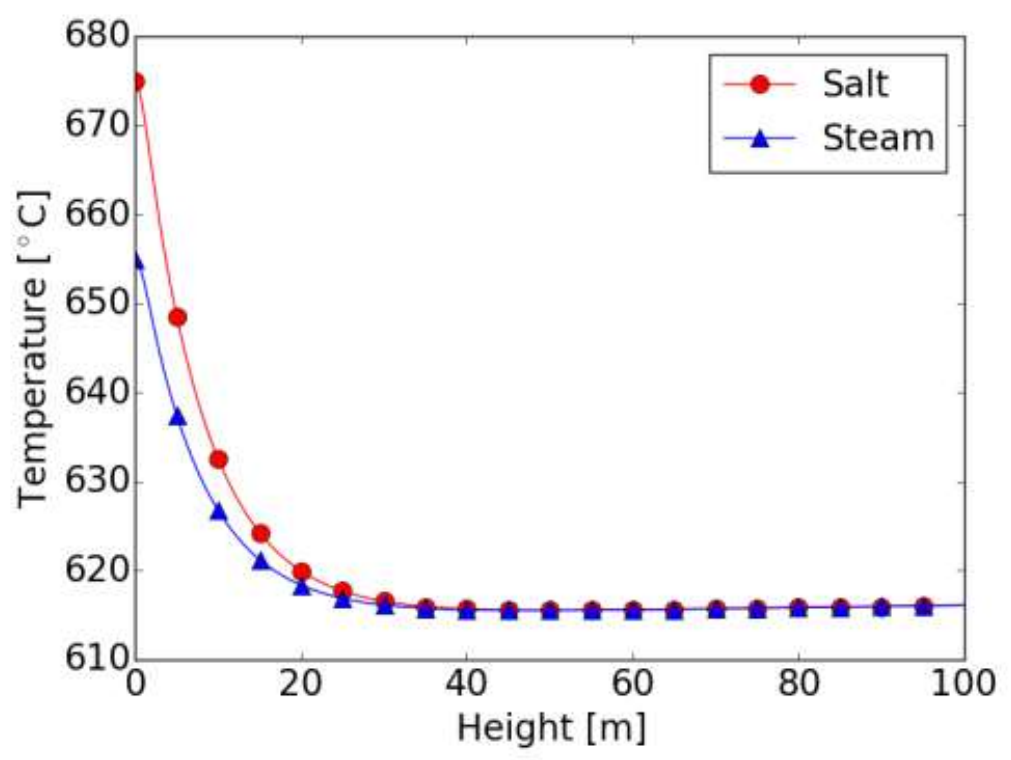

Fig. 11: Infeasible design.

The model was solved from the top of the column down to demonstrate this, however a bottom up solution results in the same problem but at the phase transition temperature instead. Overall the behaviour in Figure 10 is quite different from the urea prilling design where the objective is only to cool the urea whereas in the current case an additional objective is to generate a high temperature gas stream for turbine steam generation.

From a crude optimization perspective, the design parameters should be chosen to minimize the capital cost and hence tower height. To this end the next segment considers the influence of various parameters on the tower height. However, it is important to verify that under the new conditions the steam/steam heat exchange system does not violate the specified $\Delta \mathrm{T}_{\min }$ at its respective pinch. For any reduction of the coolant steam temperature this does occur, as may be ascertained from Figure 6. Ignoring this limitation, the change in the required tower height as the coolant steam outlet temperature is varied is shown in Figure 12. 


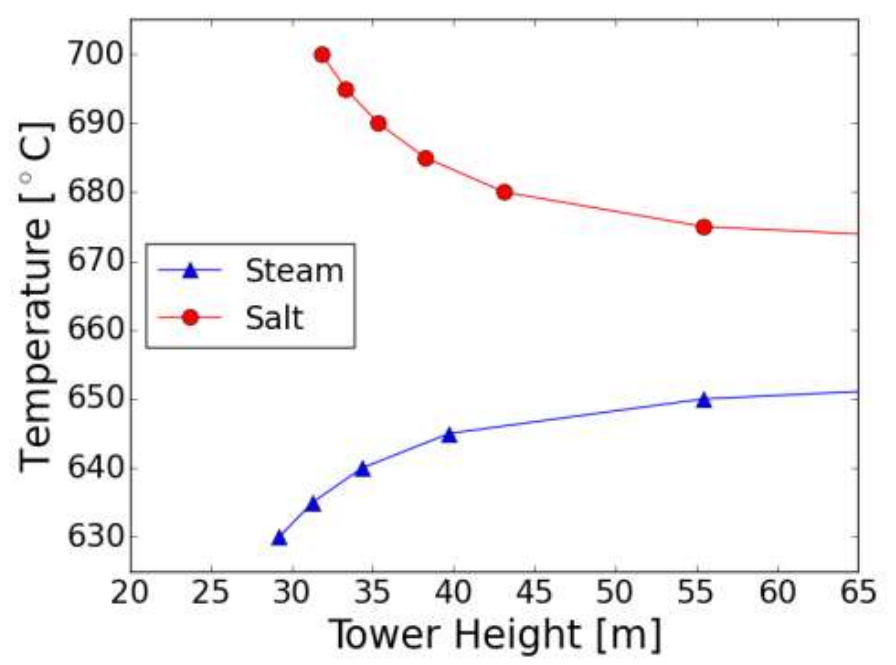

Fig. 12: Influence of maximum steam and salt temperatures on tower height.

The decreased tower height would have to be traded-off against the increased cost of the boiler due to its higher exchange area requirement at the new $\Delta T_{\min }$. An alternative approach is to keep the coolant outlet temperature at $650{ }^{\circ} \mathrm{C}$ and increase the salt inlet temperature, this is also demonstrated in Figure 12. In this case, the trade-off would be against an increased corrosion rate or possibly the requirement of an expensive specialized alloy. This configuration has the additional benefits of slightly reducing the salt flow rate and no change in the steam/steam heat exchanger system. The next parameter which was investigated is the column pressure, for which the impact on the tower height is given in Figure 13.

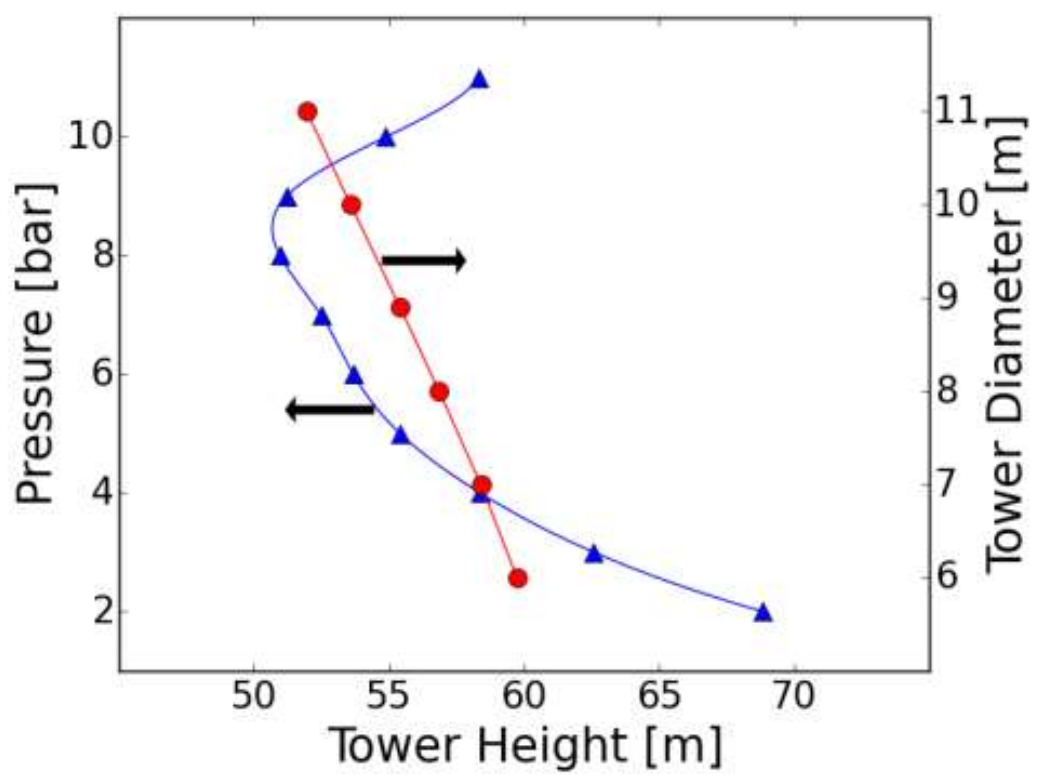

Fig. 13: Influence of tower pressure and diameter on tower height. 
Variation of the tower pressure actually results in an optimal value in terms of tower height at around 8 bar. The reason for this is a trade-off between two conflicting consequences of raising the column pressure, namely the heat capacity of the steam is increased but at the same time the saturation temperature is also increased, thus limiting the operable temperature range. As can be seen from this figure this relationship is very non-linear. The tower diameter on the other hand appears to have the opposite effect to what might be initially expected. As the diameter is decreased the air velocity is increased (at the same mass flow rate), thus increasing the Reynolds number and consequently the heat transfer coefficient. However, the higher velocities significantly reduce the contact time between the coolant and particles, resulting in less heat transfer per meter of column height. This necessitates a higher tower, however increasing the tower diameter beyond a certain value may result in an uneven or too disperse distribution of solid particles for efficient contacting. In addition, the tower cost will increase especially under pressurized operation. Finally, the influence of the particle diameter on the tower was considered as revealed in Figure 14.

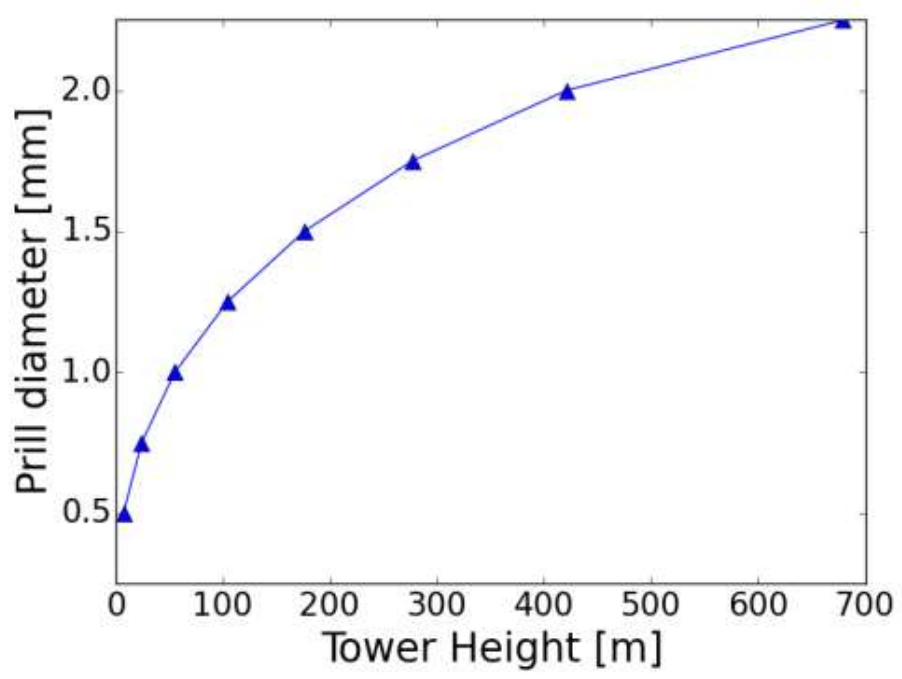

Fig. 14: Influence of particle diameter on tower height.

It is clear this parameter has by far the most substantial impact on the tower design. The reason relates back to the initial motivation for this investigation: the low heat transfer which is achieved during phase transition. The mass of PCM which must be solidified scales with diameter to the power of three, which results in the observed 
cubic increase in the required tower height. This result further demonstrates the need for a critical analysis of the prilling feed system. If a particle distribution with a mean diameter of around $1 \mathrm{~mm}$ is not achievable, the operating parameters will have to be significantly adjusted from those proposed in section 2.4. As already mentioned in section 2.5 , if the approach temperature, $\Delta \mathrm{T}_{\min }=25^{\circ} \mathrm{C}$, is reduced a feasible design may be found for larger diameter particles.

On the other hand, if the mean prill diameter can be controlled at around $1 \mathrm{~mm}$ or less, the system is achievable under the given operating conditions. Furthermore, since the current Gemasolar solar power tower is in fact $140 \mathrm{~m}$ high, whereas the required height is only $55 \mathrm{~m}$, it may even be possible to subdivide the tower into roughly three sections, running in parallel. This would bring the feed rate per "sub tower" to around $22 \mathrm{~kg} \cdot \mathrm{s}^{-1}$, which is very close to the industrial design presented by Alamdari et al. [29]. Nonetheless, a lot of additional experimental work is required to generate design information for the prilling feed system for operation at the high temperatures and with the salts proposed in the current investigation.

A related parameter is the inlet velocity of the prills, which is also dependent on the feed system design. The impact of the initial salt velocity on tower height requirement was found to be negligible. The particles very rapidly slow down due to frictional forces with the air if they are injected at high velocities or accelerate slightly if they are admitted at very low velocities. The reason is that the momentum balance is an interchange between gravitational acceleration and air friction. Since the mass of the particle is fixed, the gravitational force is fixed and so is the air velocity, thus the balancing point between these two forces remains more or less constant. However, it is very likely that this parameter will significantly impact on the achievable prill diameter. Preliminary indications are that higher velocities will be required to induce liquid jet break-up in order to achieve the smallest possible droplet sizes [21].

To compare the performance of the different case studies, the results are summarized in Table 4. 
Table 4: Performance comparison of case studies.

\begin{tabular}{|cc|c|c|c|}
\hline Case study & $\begin{array}{c}\text { Salt flow rate } \\
\left(\mathrm{kg} . \mathrm{s}^{-1}\right)\end{array}$ & $\begin{array}{c}\text { Gas flow rate } \\
\left(\mathrm{kg} \cdot \mathrm{s}^{-1}\right)\end{array}$ & $\begin{array}{c}\text { Tower height } \\
(\mathrm{m})\end{array}$ \\
\hline 1) & Base case & 150 & - & 140 \\
\hline 2) & Retrofit & 109 & 82 & - \\
\hline 3) & Greenfields & 66.7 & 56.9 & - \\
\hline 4) & Idealized & 53.2 & $\begin{array}{c}56.9 \text { (steam) } \\
+41.7 \text { (air) }\end{array}$ & \\
\hline
\end{tabular}

For the base case a storage capacity of 15 hours was implemented. At full load capacity this would require $8100 \mathrm{~kg}$ of solar salt. For the greenfields implementation this can be reduced by more than half to $3600 \mathrm{~kg}$. From a capital cost perspective this implies a $15 \%$ saving on the overall plant cost. This is a significant saving which in a "best-case" scenario could be further reduced to just over $20 \%$.

Since the central receiver tower is already part of the cost of the plant, the use of this as a prilling tower would only add minimal costs in terms of the feed system. However, the steam generation system will change from a liquid-liquid vaporizer and gas-liquid super and re-heaters to gas-liquid and gas-gas systems respectively. For this there would be an additional cost increase due to the higher exchange area required. In addition, the solids handling equipment will add to the cost, although this can be limited by cooling the salt to ambient temperature. The solar receiver is somewhat different from the system currently in use, but it is uncertain whether the cost will be significantly impacted.

Thus it is clear that several key research areas remain where detailed investigations must be made to generate a conclusive techno-economic evaluation. However, taking all these factors into account it is apparent that the proposed system to use a prilling tower for rapid heat extraction from PCMs for a latent heat thermal energy storage system in SPTs is feasible and economically attractive.

\section{Conclusions and recommendations}

Latent heat thermal energy storage using PCMs remains one of the most attractive options for industrial scale deployment of CSP technologies and specifically SPTs. However, the rapid extraction of thermal energy from these storage systems remains a key stumbling block. To overcome this hurdle, a fresh and innovative heat exchanger 
design concept is required which is tailored to this two phase system. For this purpose a prilling process integrated directly into the central receiver tower of an SPT design has been proposed to swiftly extract the heat from small solid particles.

The Gemasolar plant in Spain was used as the base case for comparison of the system design and operation. In addition, three case studies were considered: 1) retrofitting the Gemasolar plant; 2) a new greenfields plant and 3) an idealized design option. The investigation demonstrated that it is critical to consider the prilling heat exchanger in conjunction with the steam generation cycle to ensure that this secondary system operates at a sufficient distance from its pinch point. Using the solar salt in use at Gemasolar, it was found that an additional 16.4 MW of energy could be recovered through prilling. This reduced the required salt circulation rate by almost $30 \%$. However, this only resulted in partial solidification of the solid, with further heat extraction limited by pinch considerations on the turbine steam generation.

The greenfields design enabled a new choice of salt for which a potassium halide mixture was chosen due to its high enthalpy of fusion and competitive market value. Initially, air was considered as the coolant but due to its low heat capacity, steam was chosen instead. This places a lower limit on the operational temperature of the system to avoid condensation of the steam which is dependent on the tower pressure. Due to this the heat recovery from the salt is still limited and the maximum possible energy storage density could not be achieved. Nonetheless, this configuration resulted in a further reduction of the required salt flow rate to more than half of the base case requirement.

This case was investigated in detail to determine the system sensitivity to the design parameters. The following key findings were made:

1) Decreasing the delta temperature between the salt inlet and coolant outlet led to the development of a pseudo-pinch point which increases tower height

2) Raising the salt inlet temperature leads to improved performance but increased corrosion may necessitate the use of specialized alloys

3) The tower pressure has an optimal operating point of 8 bar due to a trade-off between improved coolant heat capacity and higher saturation temperature

4) Decreasing the diameter of the tower acts to reduce the amount of cooling due to limited contact time, increasing the required tower height. 
5) The largest single impact on the tower height requirement is the particle size, which drastically increases the required height as the prill diameter is increased

A simplified receiver design has been suggested, but a more detailed design is required to ensure its practical viability. In addition, the prilling feed system has been pinpointed as the most important focal point for future experimental investigation. This unit has an essential impact on several key design variables, such as the achievable particle size distribution, salt inlet velocity and space requirements for even distribution of particles in the tower.

As a comparison, an idealized "best case scenario" was also proposed which led to a further reduction in the salt requirement to roughly one third of the base case value. This resulted in an overall capital cost saving for the plant of $20 \%$ in terms of the required storage material costs. However, a more detailed analysis and a full technoeconomic design optimization of the fully integrated system must be done to arrive at a definitive conclusion.

Nevertheless, the objective of this investigation was to conduct a preliminary verification of the feasibility of the solar power tower prilling concept. Based on the simulation results the design is an appealing option for making industrial scale latent heat energy storage viable and economically attractive thus it should be pursued further. Another key outcome of the study was to identify several critical aspects for future experimental investigations in order to refine the operational estimates. This will allow the model to be improved by incorporating considerations such as prill size distribution, non-isothermal prill temperatures and different salt choices.

\section{References}

[1] European Commission. Concentrating solar power - From research to implementation. Published in Luxembourg by Office for Official Publications of the European Communities; 2007. ISBN 978-92-79-05355-9. ec.europa.eu.

[2] Sargent \& Lundy LLC Consulting Group. Assessment of parabolic trough and power tower solar technology cost and performance forecasts. Report NREL/SR550-34440, NREL (National Renewable Energy Laboratory), Golden, CO,USA; 2003. 
[3] Behar O, Khellaf A, Mohammedi K. A review of studies on central receiver solar thermal power plants, Renew. Sustain. Energy Rev. 2013;23:12-39.

[4] Luo Y, Du X, Wen D. Novel design of central dual-receiver for solar power tower. Appl. Therm. Eng. 2015;91:1071-81.

[5] Khan J, Arsalan MH. Solar power technologies for sustainable electricity generation - A review. Renew. Sustain. Energy Rev. 2016;55:414-25.

[6] Amadei CA, Allesina G, Tartarini P, Yuting W. Simulation of GEMASOLARbased solar tower plants for the Chinese energy market: Influence of plant downsizing and location change. Renewable Energy 2013;55:366-73.

[7] Burgaleta JI, Arias S, Ramirez D. Gemasolar, the First Tower Thermosolar Commercial Plant with Molten Salt Storage. Energy Procedia 2015;69,1660-6.

[8] Torresol Energy. Information about Gemasolar plant. Available from: http://www.torresolenergy.com/TORRESOL/gemasolar-plant/en; last retrieval on 01/12/2015.

[9] Azcárraga G. International Solar Energy Society: Evaluating the effectiveness of molten salt storage with solar plants. Available from: https://www.ises.org/fileadmin/user_upload/PDF/Molten_salt_tower_plant_GA_A zcarraga.pdf; last retrieval on 01/12/2015.

[10] Khare S, Dell'Amico M, Knight C, McGarry S. Selection of materials for high temperature latent heat energy storage. Sol. Energy Mater. Sol. Cells 2012;107:207.

[11] Desideri U, Campana PE, Analysis and comparison between a concentrating solar and a photovoltaic power plant. Appl. Energy 2014;113:422-33.

[12] Kuravi S, Trahan J, Goswami DY, Rahman MM, Stefanakos EK. Thermal energy storage technologies and systems for concentrating solar power plants, Prog. Energy Combust. Sci. 2013;39:285-319.

[13] Zeng J, Zheng S, Yu S, Zhu F, Gan J, Zhu L, et al. Preparation and thermal properties of palmitic acid/polyaniline/exfoliated graphite nanoplatelets formstable phase change materials. Appl. Energy 2014;115:603-9.

[14] Zhang L, Zhu J, Zhou W, Wang J, Wang, Y. Thermal and electrical conductivity enhancement of graphite nanoplatelets on form-stable polyethylene glycol / polymethyl methacrylate composite phase change materials. Energy 2012;39:294302 
[15] Fang Z, Fan L, Ding Q, Wang X, Yao X, Hou J, et al. Increased Thermal Conductivity of Eicosane-Based Composite Phase Change Materials in the Presence of Graphene Nanoplatelets. Energy Fuels 2013;27:4041-7.

[16] Ji H, Sellan DP, Pettes MT, Kong X, Ji J, Shi L, et al. Enhanced thermal conductivity of phase change materials with ultrathin-graphite foams for thermal energy storage. Energy Environ. Sci. 2014;7:1185-92.

[17] Li M, Wu Z, Tan J. Properties of form-stable paraffin/silicon dioxide/expanded graphite phase change composites prepared by sol-gel method. Appl. Energy 2012;92:456-61.

[18] Xiao X, Zhang P, Li M. Thermal characterization of nitrates and nitrates/expanded graphite mixture phase change materials for solar energy storage. Energy Convers. Manage. 2013;73:86-94.

[19] Sarı A, Alkan C, Altıntaş A. Preparation, characterization and latent heat thermal energy storage properties of micro-nanoencapsulated fatty acids by polystyrene shell. Appl. Therm. Eng. 2014;73:1160-8.

[20] Gowariker V, Krishnamurthy N, Gowariker S, Dhanorkar M, Paranjape K. The Fertilizer Encyclopedia. New Jersey: John Wiley \& Sons; 2009.

[21] Partridge L, Wong DCY, Simmons MJH, Părău EI, Decent SP. Experimental and theoretical description of the break-up of curved liquid jets in the prilling process. Chem. Eng. Res. Des. 2005;83:1267-75.

[22] Gurney CJ, Simmons MJH, Hawkins VL, Decent SP. The impact of multifrequency and forced disturbances upon drop size distributions in prilling. Chem. Eng. Sci. 2010;65:3474-84.

[23] Lapple CE, Shepherd CB. Calculation of particle trajectories. Ind. Eng. Chem. 1940;32:605-17.

[24] Hughes RP, Gilliland ER. The mechanics of drops. Chem. Eng. Prog. 1952;48:497-504.

[25] Schweizer P, Covell B, Widmer F. Dimensions of a prill tower. Chimia 1975;29:78-84.

[26] Vinaberg AM, Mukosei VI, Beskov VS. Mathematical modelling of granulation from melts and its use for the design of granulation towers. Tr. Gos. N.-i i Proekt. In ta Azot. Rom-sti i Productov Organ. Sinteza 1976;40:48-58. 
[27] Hassanien S, El Safty M. Mathematical modelling for drying prilling towers. Trans. Egyptian Soc. Chem. Eng. 1985;11:61-71.

[28] Taran AL, Taran AV. Granulation of one component melt by dispersion into an ascending coolant stream. Inzh-Fiz. Zh. 1986;51:60-68.

[29] Alamdari A, Jahanmiri A, Rahmanian N. Mathematical modelling of urea prilling process. Chem. Eng. Comm. 2000;178:185-98.

[30] Siemens. Steam turbines for CSP plants. Available from: http://www.energy.siemens.com/br/pool/hq/power-generation/steam-turbines/ ; last retrieval on $01 / 12 / 2015$.

[31] Badenhorst H. Performance comparison of three models for thermal property determination from experimental phase change data. Thermochim. Acta 2015;616:69-78.

[32] Hollands KGT. An analysis of a counter flow spray cooling tower, Int. J. Heat and Mass Transfer 1974;17:1227-39.

[33] Kunii D, Levenspiel S. Fluidization Engineering. Boston: ButterworthHeinemann; 1991.

[34] Kenisarin MM. High-temperature phase change materials for thermal energy storage, Renew. Sustain. Energy Rev. 2010;14:955-970.

[35] Kruizenga A, Gill D. Corrosion of iron stainless steels in molten nitrate salt. Energy Procedia. 2014;49:878-87.

[36] Zheng G, Kelleher B, Cao G, Anderson M, Allen T, Sridharan K. Corrosion of 316 stainless steel in high temperature molten $\mathrm{Li}_{2} \mathrm{BeF}_{4}(\mathrm{FLiBe})$ salt. J. Nucl. Mater. 2015;461:143-50.

[37] Shankar AR, Mudali UK. Corrosion of type 316L stainless steel in molten

LiCl-KCl salt. Mater. Corros. 2008;59:878-82.

[38] Ochkov VF, Orlov KA, Aleksandrov AA, Ochkov, AV. Properties of water and steam: Network, open, and interactive IT-resources. Therm. Eng. 2015;62:378-87.

[39] Wu Y, Bao C, Zhou Y. An innovated tower-fluidized bed prilling process. Chin. J. Chem. Eng. 2007;15:424-8.

[40] Oles AS, Jackson GS. Modeling of a concentrated-solar, falling-particle receiver for ceria reduction. Sol. Energy 2015;122:126-47.

[41] Tan T, Chen Y, Chen Z. Parametric study on the performance of a solid particle solar receiver. Sol. Energy 2015;120:277-86. 
[42] Rahmanian N, Homayoonfard M, Alamdari A. Simulation of urea prilling process an industrial case study. Chem. Eng. Comm. 2013;200:764-82. 